\title{
Suv4-20h2 mediates chromatin compaction and is important for cohesin recruitment to heterochromatin
}

\author{
Matthias Hahn, ${ }^{1,2,9}$ Silvia Dambacher, ${ }^{1,2,9}$ Stanimir Dulev, ${ }^{1,2}$ Anastasia Yurievna Kuznetsova, ${ }^{3}$ \\ Simon Eck, ${ }^{4,5}$ Stefan Wörz, ${ }^{4,5}$ Dennis Sadic,, ${ }^{1,2}$ Maike Schulte, ${ }^{1,2}$ Jan-Philipp Mallm, ${ }^{5,6}$ \\ Andreas Maiser, ${ }^{1,7}$ Pierre Debs, ${ }^{8}$ Harald von Melchner, ${ }^{8}$ Heinrich Leonhardt, ${ }^{1,7}$ \\ Lothar Schermelleh, ${ }^{1,7,10}$ Karl Rohr, ${ }^{4,5}$ Karsten Rippe, ${ }^{5,6}$ Zuzana Storchova, $^{3}$ and Gunnar Schotta ${ }^{1,2,11}$ \\ ${ }^{1}$ Munich Center for Integrated Protein Science $\left(\mathrm{CiPS}^{\mathrm{M}}\right)$, Ludwig Maximilians University; ${ }^{2}$ Adolf-Butenandt-Institute, 80336 \\ Munich, Germany; ${ }^{3}$ Max Planck Institute of Biochemistry, 82152 Martinsried, Germany; ${ }^{4}$ Department of Bioinformatics \\ and Functional Genomics, Biomedical Computer Vision Group, Institut für Pharmazie und Molekulare Biotechnologie \\ (IPMB), BioQuant, University of Heidelberg, 69120 Heidelberg, Germany; ${ }^{5}$ Deutsches Krebsforschungszentrum (DKFZ) \\ Heidelberg, 69120 Heidelberg, Germany; ${ }^{6}$ Research Group Genome Organization and Function, BioQuant, 69120 \\ Heidelberg, Germany; ${ }^{7}$ Department of Biology II, Biozentrum, 82152 Munich, Germany; ${ }^{8}$ Department of Molecular \\ Hematology, University of Frankfurt Medical School, 60590 Frankfurt am Main, Germany
}

Cohesin plays an important role in chromatid cohesion and has additional functions in higher-order chromatin organization and in transcriptional regulation. The binding of cohesin to euchromatic regions is largely mediated by CTCF or the mediator complex. However, it is currently unknown how cohesin is recruited to pericentric heterochromatin in mammalian cells. Here we define the histone methyltransferase Suv4-20h2 as a major structural constituent of heterochromatin that mediates chromatin compaction and cohesin recruitment. Suv4$20 \mathrm{~h} 2$ stably associates with pericentric heterochromatin through synergistic interactions with multiple heterochromatin protein 1 (HP1) molecules, resulting in compaction of heterochromatic regions. Suv4-20h mutant cells display an overall reduced chromatin compaction and an altered chromocenter organization in interphase referred to as "chromocenter scattering." We found that Suv4-20h-deficient cells display chromosome segregation defects during mitosis that coincide with reduced sister chromatid cohesion. Notably, cohesin subunits interact with Suv4-20h2 both in vitro and in vivo. This interaction is necessary for cohesin binding to heterochromatin, as Suv4$20 \mathrm{~h}$ mutant cells display substantially reduced cohesin levels at pericentric heterochromatin. This defect is most prominent in G0-phase cells, where cohesin is virtually lost from heterochromatin, suggesting that Suv4-20h2 is involved in the initial loading or maintenance of cohesion subunits. In summary, our data provide the first compelling evidence that Suv4-20h2 plays essential roles in regulating nuclear architecture and ensuring proper chromosome segregation.

[Keywords: Suv39h; Suv4-20h2; chromocenter clustering; chromosome segregation; cohesin; heterochromatin] Supplemental material is available for this article.

Received November 15, 2012; revised version accepted March 26, 2013.

Pericentric heterochromatin in mammalian cells is formed from large arrays of noncoding satellite repeat sequences. Heterochromatic domains from different chromosomes can join into large clusters (so-called chromocenters) that can be visualized as DAPI-dense regions in interphase cells. Pericentric heterochromatin is largely transcriptionally inert

\footnotetext{
${ }^{9}$ These authors contributed equally to this work.

${ }^{10}$ Present address: Department of Biochemistry, University of Oxford, Oxford OX1 3QU, United Kingdom.

${ }^{11}$ Corresponding author

E-mail gunnar.schotta@med.uni-muenchen.de

Article published online ahead of print. Article and publication date are

online at http://www.genesdev.org/cgi/doi/10.1101/gad.210377.112.
}

but serves important functions in ensuring genomic stability and accurate chromosome segregation (Peters et al. 2001; Ting et al. 2011; Zhu et al. 2011). Thus, dysregulation of heterochromatin organization leads to severe diseases and developmental defects (Hahn et al. 2010).

The major constitutive heterochromatin proteins that are thought to establish the proper chromatin structure at pericentric heterochromatin are heterochromatin protein 1 (HP1) isoforms and the histone methyltransferases Suv39h and Suv4-20h (Supplemental Fig. S1A). Suv39h enzymes induce histone H3 Lys 9 trimethylation (H3K9me3) at heterochromatic regions (Peters et al. 2001). This modification is recognized by HP1 molecules, which recruit 
Suv4-20h histone methyltransferases that subsequently establish H4K20me3 (Schotta et al. 2004, 2008). It is assumed that HP1 is a major regulator of heterochromatin organization and compaction. However, this view is challenged by the fact that HP1 proteins only transiently associate with heterochromatin (Cheutin et al. 2003). Therefore, other more constitutive components might contribute to regulating heterochromatin organization.

During mitosis, pericentric heterochromatin is important to facilitate sister chromatid cohesion. This is accomplished by cohesin complexes that connect sister chromatids at pericentric regions until anaphase onset (Salic et al. 2004; Tang et al. 2004). The cohesin ring consists of a Smc1-Smc3 dimer that is connected through the $\alpha$-kleisin subunit Scc1/Rad21 (Nasmyth 2011). Cohesin is loaded onto chromatin in early G1 phase. Sites of cohesin loading can differ from regions with the highest cohesin enrichment, and therefore the cohesin rings are assumed to slide several kilobases from the loading site (Lengronne et al. 2004), where they might be fixed by interactions with other proteins, such as CTCF (Parelho et al. 2008; Rubio et al. 2008; Wendt et al. 2008). Due to the large size and compact structure of pericentric regions, there must be loading sites within heterochromatin, and it is therefore likely that core heterochromatin proteins assist in stable cohesin recruitment within these domains. In agreement with this hypothesis, cohesin is recruited to heterochromatic regions by $\mathrm{Swi6} / \mathrm{HP} 1$ in fission yeast (Nonaka et al. 2002). However, HP1 proteins do not interact with cohesin in mammalian cells (Koch et al. 2008), and it is currently unknown how recruitment and maintenance of cohesin at pericentric heterochromatin is mediated.

In this study, we discovered an interaction between the histone methyltransferase Suv4-20h2 and cohesin. We found that Suv4-20h2 is required for cohesin recruitment to pericentric heterochromatin. Suv4-20h-deficient cells have strongly reduced cohesin levels at pericentric heterochromatin, resulting in chromosome segregation defects. Thus, our data demonstrate a novel role of the Suv39h-Suv4-20h pathway in cohesin recruitment to pericentric heterochromatin.

\section{Results}

Suv4-20h2 is a stable component of pericentric heterochromatin

We first set out to determine whether any of the heterochromatin core proteins could play structural roles in heterochromatin. We assessed their mobility in embryonic stem (ES) cells by fluorescence recovery after photobleaching (FRAP) analysis specifically at pericentric heterochromatin (Supplemental Fig. S1B). Consistent with previous reports (Cheutin et al. 2003), we found that $\mathrm{HP} 1 \alpha$ is a very mobile protein (Fig. 1A). This is a common feature of all HP1 variants, as the other isoforms-HP1 $\beta$ and $\mathrm{HP} 1 \gamma$-also displayed the same fast recovery kinetics (K Rippe, pers. comm.). The histone methyltransferases Suv39h1 and Suv4-20h1 showed intermediate mobility.
Surprisingly, Suv39h2 and Suv4-20h2 stably associate with heterochromatin, as both proteins showed almost no recovery on the minute time scale (Fig. 1A). In addition, we determined the mobility parameters of the core heterochromatin proteins in another cell system: mouse embryonic fibroblast cells (MEFs). Interestingly, the recovery kinetics of all proteins were slower as compared with ES cells, which is in agreement with the hypothesis that heterochromatin is less plastic in differentiated cells (Meshorer et al. 2006). Similarly to ES cells, we found that Suv39h2 and Suv4-20h2 exhibit the strongest binding to heterochromatin (Fig. 1A). These experiments were complemented by fluorescence correlation spectroscopy (FCS) measurements of Suv4-20h2 at endogenous expression levels (Supplemental Fig. S2). For these assays, we generated a Suv4-20h2 $2^{\text {EGFP }}$ knock-in ES cell line that expresses Suv4-20h2 at nearly endogenous levels (Supplemental Fig. S2B) and displays clear enrichment of Suv4-20h2 and H4K20me3 at pericentric heterochromatin (Supplemental Fig. S2C). FCS mobility measurements confirm that at endogenous expression levels, the mobile Suv4-20h2 binds more tightly to chromatin than HP1, since its apparent diffusion coefficient, which includes the binding contribution, is reduced (Supplemental Fig. S2D). Furthermore, the immobile pool of Suv4-20h2 was $\sim 10$ times higher than that of HP1, as determined from continuous photobleaching experiments (Supplemental Fig. S2E). Taken together, our data suggest that the histone methyltransferases Suv39h2 and Suv4-20h2 could play structural roles in pericentric heterochromatin.

\section{Stable binding of Suv4-20h2 is mediated through synergistic HP1 interactions}

The stable binding of Suv4-20h2 to heterochromatin was also demonstrated in a previous study for human SUV4$20 \mathrm{H} 2$ (Souza et al. 2009), suggesting that this feature of Suv4-20h2 is evolutionarily conserved. However, as the bulk of HP1 only transiently associates with heterochromatin, it is surprising that Suv4-20h2 can stably bind heterochromatin. Therefore, we asked how this stable association of Suv4-20h2 is mediated. The C terminus of Suv4-20h2 is responsible for heterochromatin targeting (Schotta et al. 2004). In order to better define the targeting domain, we generated a panel of EGFP-tagged Suv4-20h2 truncation proteins as subfragments of the $\mathrm{C}$ terminus (Fig. 1B). Fragment M12, which comprises only 62 amino acids of the Suv4-20h2 C terminus, showed clear pericentric enrichment (Fig. 1B; Supplemental Fig. S2F). We further subdivided this fragment and found that two nonoverlapping truncations-M13 and M14-were both able to localize to pericentric heterochromatin as well (Fig. 1B; Supplemental Fig. S2F). These data indicate that at least two independent heterochromatin targeting modules exist in Suv4-20h2. We then asked whether the M12 region is really crucial for mediating pericentric recruitment of Suv4-20h2 and tested the localization of a Suv4$20 \mathrm{~h}$ mutant protein lacking the M12 region. We did not detect enrichment of this mutant protein at pericentric 
A

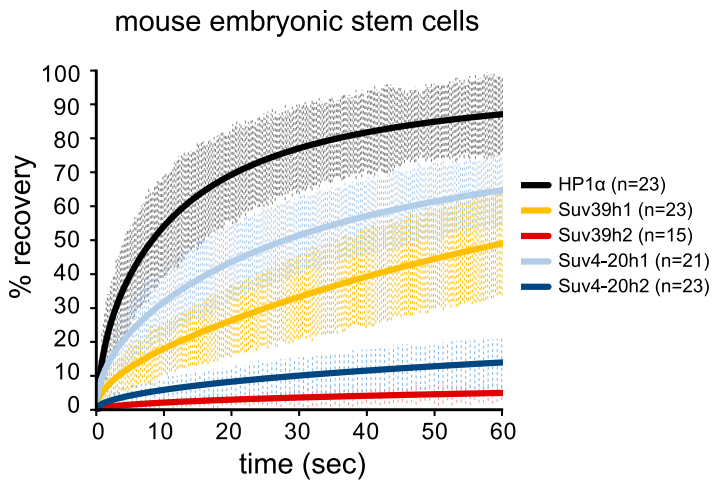

mouse embryonic fibroblasts

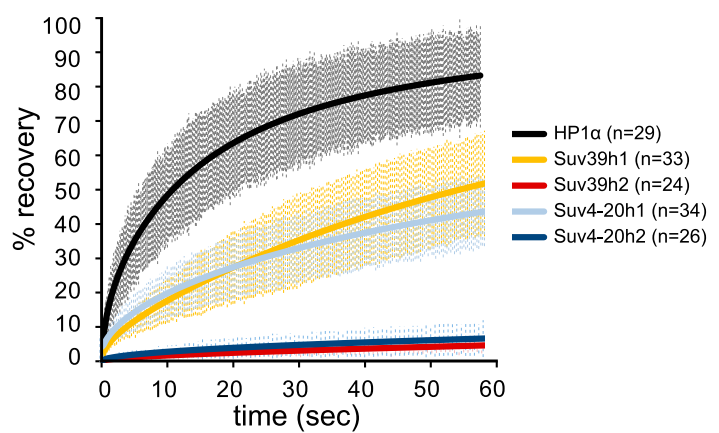

B

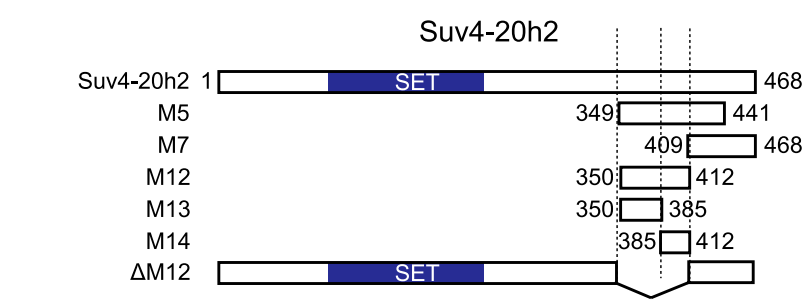

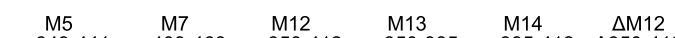

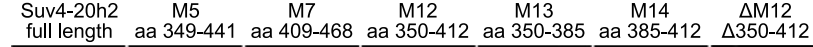
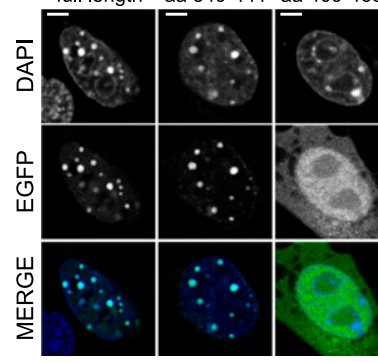

E
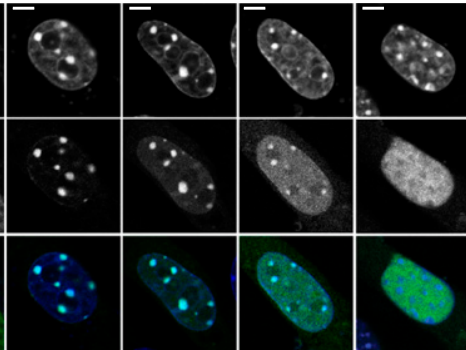

M12

D

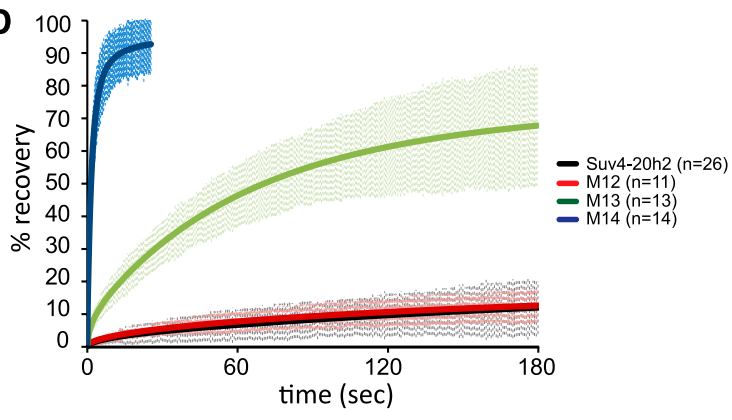

C

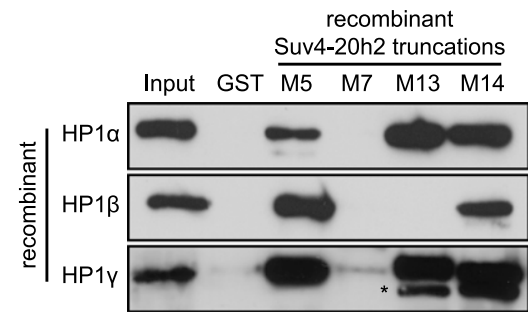

M13
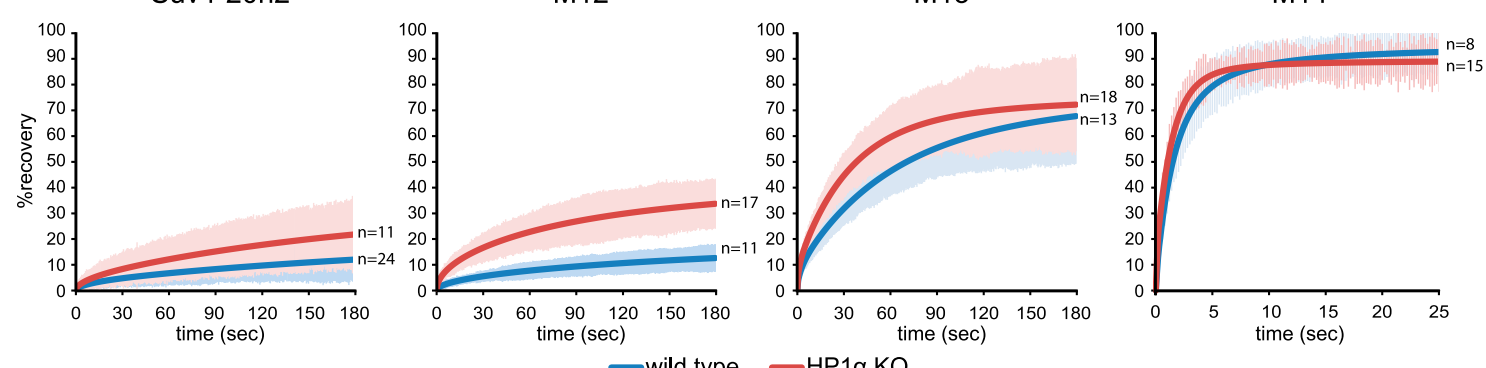

- wild type - HP1a KO

Figure 1. Suv4-20h2 is a stable component of pericentric heterochromatin. (A) FRAP analysis of core heterochromatin proteins. EGFPtagged proteins were expressed in wild-type ES cells and MEFs. Laser bleaching and analysis of fluorescence recovery were carried out specifically at pericentric heterochromatin. FRAP recovery experiments for multiple cells (indicated in the legend) were averaged and fitted to a reaction diffusion model. Error bars represent the standard deviation of the FRAP measurements in each series. (B) Distinct regions in the C terminus mediate heterochromatin localization of Suv4-20h2. (Top panel) Schematic showing Suv4-20h2 truncation proteins that were expressed as EGFP fusion proteins in wild-type MEFs. (Bottom panel) Confocal sections of MEFs expressing EGFPtagged Suv4-20h2 truncations. Bars, $5 \mu \mathrm{m}$. $(C)$ In vitro interaction test of Suv4-20h2 truncation proteins and HP1 isoforms. GST-tagged Suv4-20h2 truncation proteins were bound to GST beads and incubated with recombinant HP1 $\alpha, \mathrm{HP} 1 \beta$, and HP1 $\gamma$, respectively. Bound proteins were separated on SDS page and probed with HP1 isoform-specific antibodies. The asterisk indicates cross-reacting bands with the HP1 $\gamma$ antibody. $(D)$ FRAP kinetics of Suv4-20h2 truncation proteins at pericentric heterochromatin. The C-terminal fragment M12 is as stable as the full-length Suv4-20h2 protein. Subfragments of M12 (M13 and M14) show a much faster recovery. FRAP recovery experiments for multiple cells (indicated in the legend) were averaged and fitted to a reaction diffusion model. Error bars represent the standard deviation of the FRAP measurements in each series. (E) Suv4-20h2 is more dynamic in HP1 $\alpha$ mutant cells. Suv4-20h2 fulllength and truncation proteins were expressed in wild-type and HP1 $\alpha$ knockout cells. FRAP kinetics at heterochromatin of all Suv4$20 \mathrm{~h} 2$ truncations are faster in HP1 $\alpha$ mutant cells. FRAP recovery experiments for multiple cells (indicated in the legend) were averaged and fitted to a reaction diffusion model. Error bars represent the standard deviation of the FRAP measurements in each series. 
heterochromatin (Fig. 1B). Thus, we conclude that the region comprising amino acids 350-412 represents the heterochromatin targeting domain in Suv4-20h2.

Heterochromatin targeting of Suv4-20h2 depends on HP1 proteins (Schotta et al. 2004). We found that Suv4$20 \mathrm{~h} 2$ can interact with all three mammalian HP1 isoforms in living cells (Supplemental Fig. S3). In vitro interaction assays revealed that all Suv4-20h2 truncations that localize to heterochromatin can directly interact with HP1 isoforms (Fig. 1C). Suv4-20h2 fragment M12 could not be generated as a soluble recombinant protein. However, as fragment M5 interacts with HP1 and fragment M7 does not show interaction with HP1, we conclude that the HP1 interaction domain resides within fragment M12. This is further supported by our finding that fragments M13 and M14, which are subregions of fragment M12, strongly interact with HP1 (Fig. 1C). Interestingly, HP1 $\alpha$ and HP1 $\gamma$ appear as the major interaction partners with both M13 and M14, whereas HP1 $\beta$ only interacts with fragment M14 (Fig. 1C). These data are in line with recent reports on HP1 interaction networks that demonstrate that HP1 $\alpha$ and HP1 $\gamma$ share similar interaction partners that do not necessarily overlap with HP1 $\beta$ interactors (Vermeulen et al. 2010). In summary, these data demonstrate that Suv4-20h2 has multiple independent HP1 interaction sites within its C terminus.

We further characterized the Suv4-20h2 truncations by measuring their mobility in heterochromatin using FRAP analysis. Full-length Suv4-20h2 stably binds to heterochromatin and showed a recovery of only $\sim 10 \%$ at $3 \mathrm{~min}$ post-bleaching (Fig. 1D). The Suv4-20h2-M12 truncation behaved virtually identical to the full-length protein, indicating that this fragment comprises the essential domain that "clamps" Suv4-20h2 onto heterochromatin (Fig. 1D). We therefore refer to this region as the Suv4-20h2 "clamp domain." Notably, the mobility of the M12 subfragments M13 and M14 was much higher. While the mobility of fragment M14 was in the range of HP1, M13 was more stably bound than HP1 (Fig. 1D), suggesting that distinct regions in Suv4-20h2 mediate the stable association with heterochromatin through interactions with HP1 proteins.

To test this hypothesis, we measured the mobility of the individual Suv4-20h truncations in fibroblasts with reduced HP1 levels. HP1 $\alpha$ knockout cells retained both H3K9me3 and H4K20me3 at pericentric heterochromatin, indicating that the recruitment of Suv39h and Suv4$20 \mathrm{~h}$ enzymes to heterochromatin is not generally impaired (Supplemental Fig. S4A). Indeed, the localization of the Suv4-20h2 truncations was not altered in the absence of HP1 $\alpha$ (Supplemental Fig. S4B). However, the FRAP recovery kinetics of full-length Suv4-20h2 and truncations M12 and M13 were clearly enhanced (Fig. 1E). We did not observe faster recovery of fragment M14, as the FRAP kinetics of this fragment were already in the range of HP1 in wild-type cells. In summary, our data suggest that Suv4-20h2 is bound to heterochromatin through at least two independent interaction sites by HP1 proteins. As the individual interactions can only generate intermediate stability (M13 and M14), we postulate that synergistic interaction with multiple HP1 proteins in the Suv4-20h2 clamp domain ensures its stable association with heterochromatin.

\section{Suv4-20h2 regulates chromatin compaction}

The tight interaction of Suv4-20h2 with heterochromatin suggests a direct involvement in regulating the structure of pericentric heterochromatin. To verify this hypothesis, we performed micrococcal nuclease (MNase) chromatin accessibility assays in wild-type, Suv4-20h2 knockout, and Suv4-20h double-knockout ES cells (Schotta et al. 2008). Notably, we detected higher chromatin accessibility in both Suv4-20h2 knockout and Suv4-20h doubleknockout cells (Fig. 2A,B). The increased accessibility clearly involves heterochromatic regions, as demonstrated by Southern blotting of the digested DNA with major satellite probes (Fig. 2A,B). A similar increase in chromatin accessibility was also observed in Suv4-20hdeficient MEF cells, suggesting that Suv4-20h2 plays general roles in regulating chromatin structure (Supplemental Fig. S5). Importantly, re-expression of Suv420h2, which restores H4K20me3 (Nicetto et al. 2013), and even of the Suv4-20h2 clamp domain (M12) rescues the accessibility phenotype of Suv4-20h double-knockout cells (Supplemental Fig. S5), indicating that Suv4$20 \mathrm{~h} 2$ can induce chromatin compaction through its clamp domain.

Superresolution three-dimensional (3D) structured illumination microscopy (3D-SIM) is a recently developed technique that allows imaging of subcellular structures below the optical diffraction limit (Schermelleh et al. 2008). Using this technique, we detected a slightly reduced chromatin density in Suv4-20h double-knockout cells around the nuclear envelope (Fig. 2C; Supplemental Fig. S6). We quantified these data by measuring the DAPI intensity of the nuclear periphery compared with the overall DAPI intensity of the nuclei (Supplemental Fig. S6B). These data indicate that wild-type nuclei have a generally higher chromatin density in the nuclear periphery as compared with Suv4-20h double-knockout cells (Supplemental Fig. S6C). Interestingly, this reduction in peripheral heterochromatin correlates with changes in the distribution of nuclear pores, which are more stochastically arranged in Suv4-20h double-knockout nuclei (Fig. 2C). Strong overexpression of Suv4-20h2 results in dramatic changes of the nuclear structure, most notably in increased chromatin compaction around chromocenters, nucleoli, and the nuclear envelope (Fig. 2C; Supplemental Fig. S6A). The increased density of the peripheral heterochromatin upon overexpression of Suv4-20h2 is again reflected in the altered distribution of nuclear pores, which tend to be excluded from the highly compacted regions. In order to quantify the effect of Suv4-20h2 on nuclear pore organization, we developed an automatic 3D image analysis approach to measure nuclear pore parameters in our 3D-SIM images (Supplemental Fig. S6D). In agreement with the qualitative analysis of the nuclear pore staining, we found that the percentage of regions with low nuclear pore density (sparse nuclear pore regions) was 
A

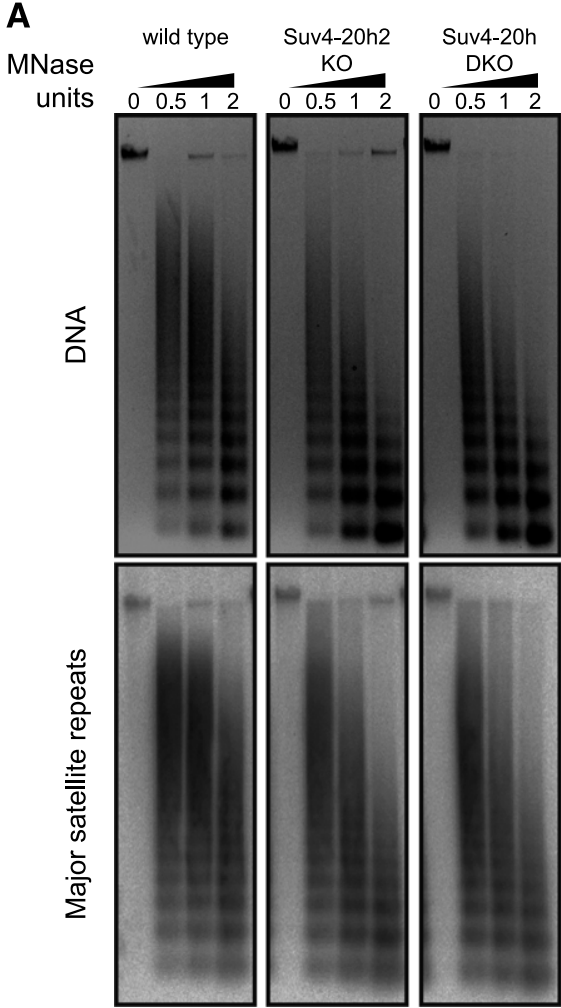

C
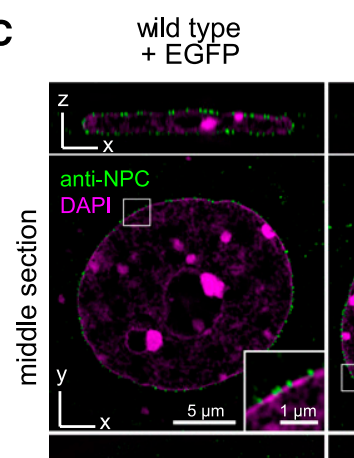

B
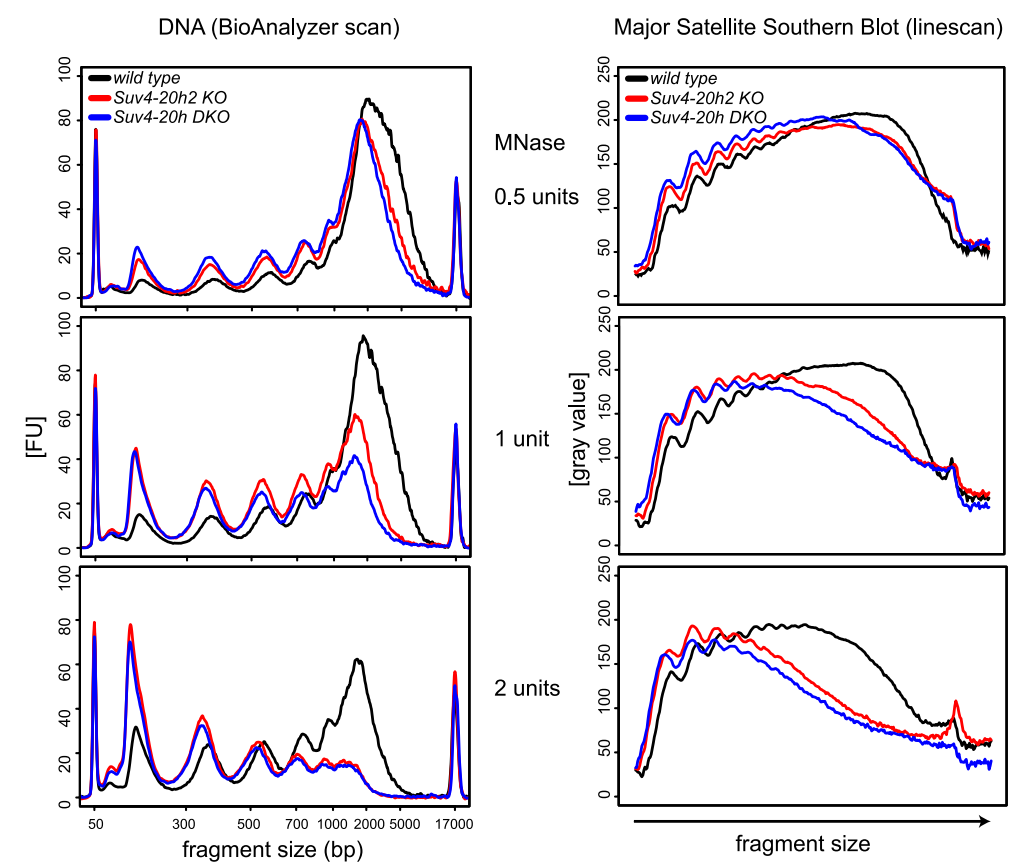

Suv4-20h DKO + EGFP

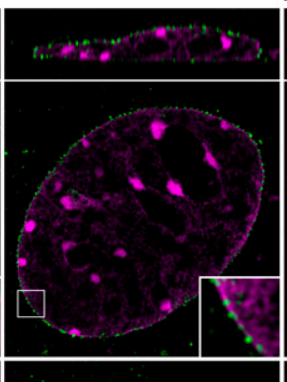
+ Suv4-20h2-EGFP

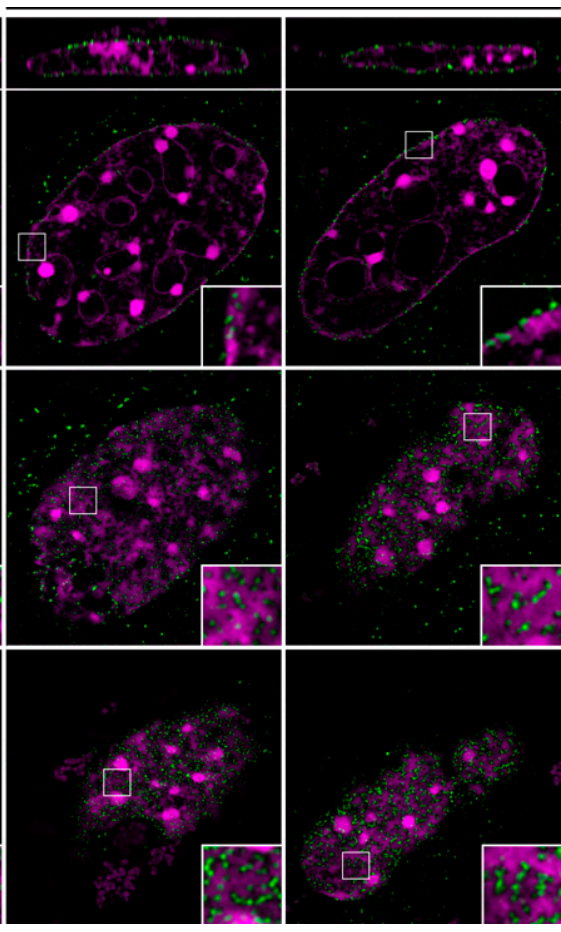

Figure 2. Suv4-20h2 mediates chromatin compaction. (A) MNase accessibility assay. Nuclei from wild-type, Suv4-20h2 knockout, and Suv4-20h double-knockout ES cells were isolated and incubated with increasing amounts of MNase. (Top panel) The digested DNA was purified, separated on agarose gels, and stained with ethidium bromide. (Bottom panel) Heterochromatic regions were visualized by Southern blotting using a major satellite-specific probe. ( $B$, left panel) Overlay of DNA electropherograms obtained from Bioanalyzer runs of the MNase-digested DNA from wild-type, Suv4-20h2 knockout, and Suv4-20h double-knockout ES cells. The first and the last sharp peaks represent the markers of the Agilent DNA 12000 kit. (FU) Fluorescence units. (Right panel) Intensity line scan of major satellite Southern blots. Gray values correspond to signal intensities of the Southern blot. (C) 3D-SIM sections of wild-type and Suv4$20 \mathrm{~h}$ double-knockout fibroblasts as well as wild-type cells overexpressing Suv4-20h2-EGFP. Immunofluorescence staining with an antiNPC antibody marks nuclear pores. Insets show enlargements of the nuclear envelope. Quantifications of peripheral heterochromatin density and nuclear pore distribution are shown in Supplemental Figure S6. 
Hahn et al.

reduced in Suv4-20h double-knockout cells and increased in cell overexpressing Suv4-20h2 (Supplemental Fig. S6E).

We further asked which part of Suv4-20h2 would be responsible for the compaction phenotype. Overexpression of the $\mathrm{N}$ terminus containing the SET domain does not lead to obvious alterations of the nuclear structure (Supplemental Fig. S7). In contrast, the C terminus of Suv4-20h2 is very potent in inducing chromatin compaction (Supplemental Fig. S7). The Suv4-20h2 clamp domain does not show a compaction phenotype. Interestingly, these data show that Suv4-20h2 has important roles in regulating nuclear architecture, which is independent of its function as a histone methyltransferase.

\section{Chromocenter scattering in Suv4-20h-deficient cells}

Our data so far demonstrate that Suv4-20h2 is a major regulator at different levels of chromatin organization in vivo. On the one hand, the observed alterations in chromatin accessibility suggest that Suv4-20h2 regulates compaction of chromatin fibers. On the other hand, the structural changes in Suv4-20h-deficient and overexpressing cells indicate that Suv4-20h2 might even mediate long-range interactions between chromatin domains. We therefore investigated whether organization of pericentric heterochromatin is altered in Suv4-20h doubleknockout cells. In mouse cells, heterochromatic regions of different chromosomes interact and form clusters, which are well discernible by DAPI staining. How this clustering is mediated is unknown. In order to visualize pericentric heterochromatin very precisely, we performed fluorescence in situ hybridization (FISH) detection of major satellite repeats in G0-arrested cells to investigate the steady-state situation of heterochromatin in the absence of cell cycle perturbations (Fig. 3A). Stacks of confocal images were evaluated using an image segmentation procedure to detect and measure individual FISH foci (Supplemental Fig. S8). In wild-type cells, we detected $\sim 25-30$ foci (Fig. 3A,B), which is consistent with previous data on chromocenter clustering in mouse fibroblasts (Guenatri et al. 2004). Suv4-20h double-knockout cells, in contrast, showed chromocenter scattering, as we observed significantly more foci per nucleus (Fig. 3A,B; Supplemental Fig. S9). At the same time, the average focus volume was smaller in the mutant cells (Fig. 3B). Notably, re-expression of full-length Suv4-20h2 in Suv4-20h double-knockout cells (DKO+FL) restores the altered nuclear organization of pericentric heterochromatin close to wild-type levels (Fig. 3B). Re-expression of the Suv4-20h2 clamp domain (M12) did not lead to a significant rescue (Fig. 3B; Supplemental Fig. S9), suggesting that although the clamp domain of Suv4-20h2 is necessary and sufficient to induce chromatin compaction as measured by MNase accessibility, additional features of the full-length protein are required to mediate long-range chromatin interactions like chromocenter clustering. Therefore, we asked whether chromocenter organization can be restored by a Suv4-20h2 mutant protein lacking methyltransferase activity (Nicetto et al. 2013). Re-expression of Suv4-20h2 $2^{\mathrm{N} 182 \mathrm{~A}, \mathrm{Y} 217 \mathrm{~A}}$ $\left(\mathrm{SET}^{\star}\right)$ could not significantly reduce chromocenter
A

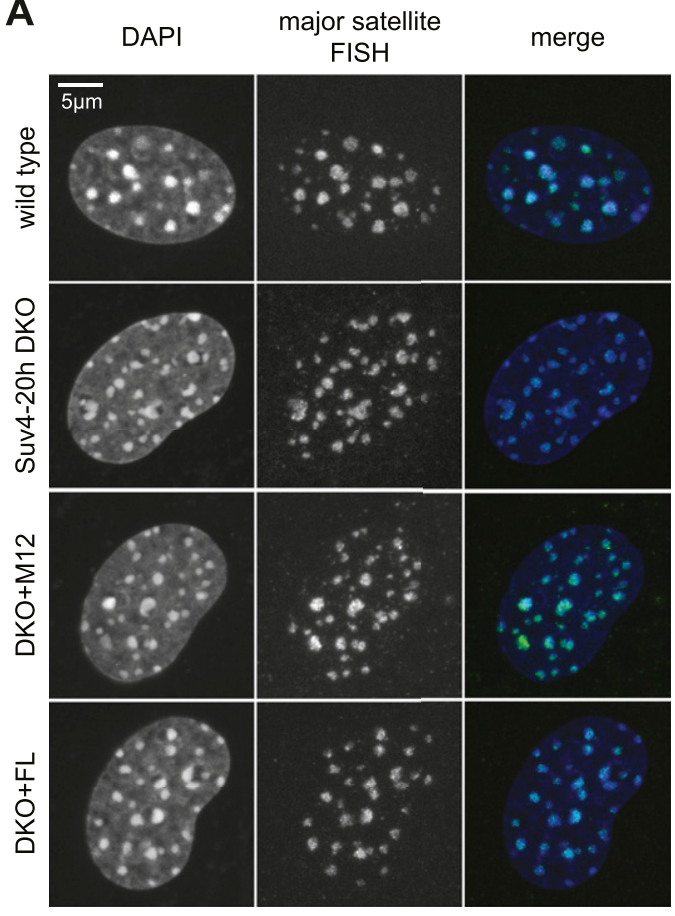

B
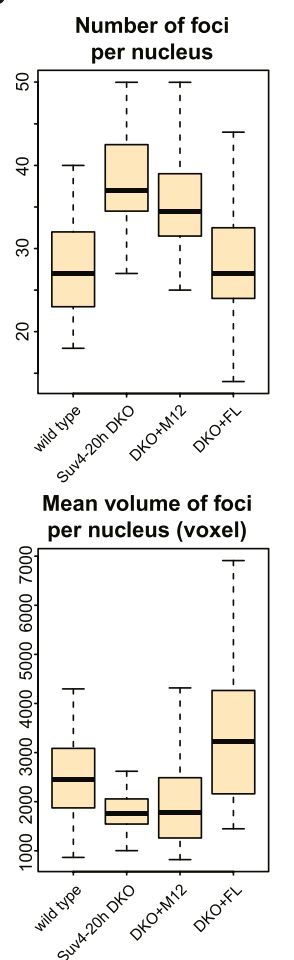

Figure 3. Suv4-20h-deficient cells display chromocenter scattering. (A) FISH analysis of major satellite repeats in G0-phase wild-type, Suv4-20h doubleknockout, and Suv4-20h2 rescue cells expressing Suv4-20h2 full-length protein (DKO+FL) or the Suv4-20h2 clamp domain (DKO+M12). (B) Quantification of major satellite FISH analyses. Chromocenter foci were counted and measured using an image segmentation analysis of confocal 3D stacks. Box plots showing the numbers of chromocenters and the chromocenter volume in wild-type $(n=43)$, Suv4-20h double-knockout $(n=35), \mathrm{DKO}+\mathrm{FL}(n=$ $28)$, and DKO+M12 $(n=24)$ nuclei. The mean number of foci per nucleus is significantly different between wild-type and Suv4-20h double-knockout as well as between Suv4-20h double-knockout and DKO+FL. Detailed statistical tests are provided in the Supplemental Material and in Supplemental Figure S9. 
scattering (Supplemental Fig. S10), indicating that establishment of H4K20me3 is important for normal chromocenter organization.

Based on our data, we propose that Suv4-20h2 can mediate interactions between chromatin fibers by binding to H3K9me3-rich and HP1-rich domains. Loss of Suv4-20h enzymes would lead to a compromised heterochromatin organization, although $\mathrm{H} 3 \mathrm{~K} 9 \mathrm{me} 3$ and $\mathrm{HP} 1$ are still present at heterochromatic regions.

\section{Suv4-20h-deficient cells display chromosome segregation defects}

Defects in heterochromatin organization often coincide with genomic instability. Therefore, we examined Suv4$20 \mathrm{~h}$ mutant cells for chromosome segregation defects by analyzing mitotic figures. Significantly more mitotic abnormalities, such as anaphase bridges and lagging chromosomes, could be observed in the Suv4-20h double-knockout cells (Fig. 4A). These defects can be rescued by expression of Suv4-20h2 full-length protein (DKO+FL) and even by expression of the Suv4-20h2 clamp domain (DKO+M12), demonstrating that Suv4-20h2 is important for proper chromosome segregation (Fig. 4A).

An analysis of different mitotic stages revealed that the segregation defects are not due to an altered progression through mitosis (Supplemental Fig. S11). Therefore, we tested whether key checkpoint proteins (AurB and Sgo1) or HP1 were altered in the absence of Suv4-20h enzymes. No obvious difference for either of these proteins was observed. However, we found that the centromere distance, as measured by the distance between adjacent CenpA foci, was wider in Suv4-20h double-knockout cells (Fig. 4B). Statistical evaluation confirmed an, on average, $100-\mathrm{nm}$ increased centromere distance in mitotic spreads of Suv4-20h double-knockout cells (Fig. 4C).
A

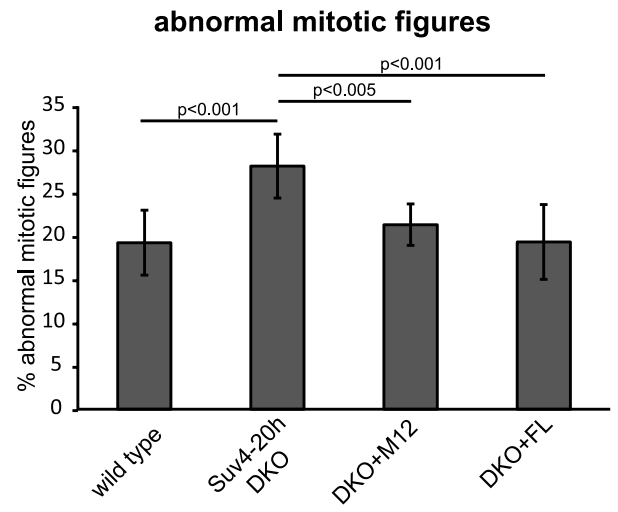

B

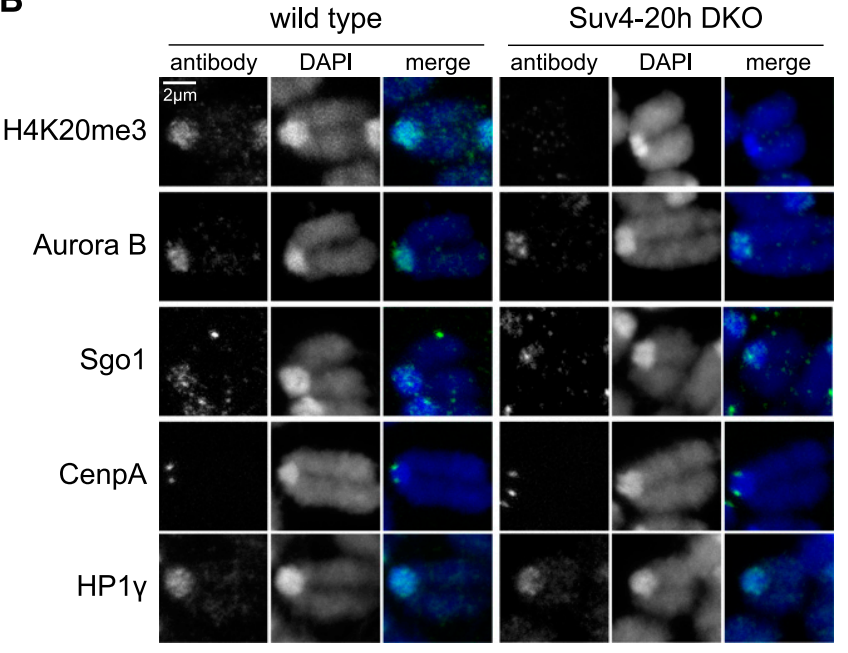

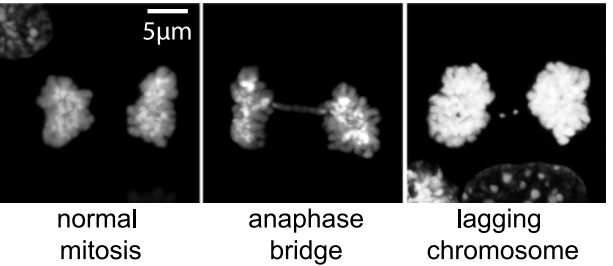

C

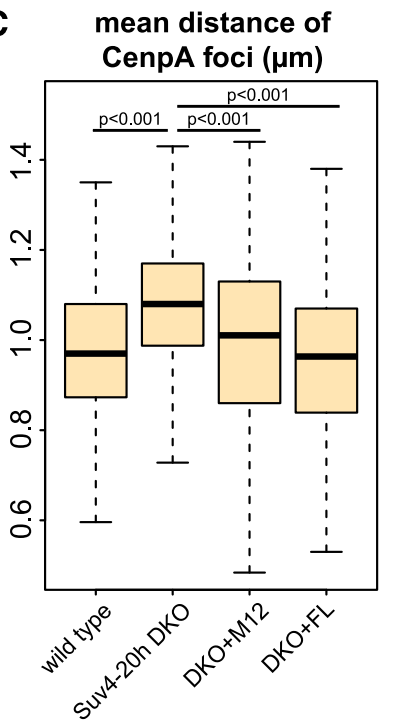

Figure 4. Suv4-20h mutants display chromosome segregation defects. (A) Suv4-20h mutant cells have mitotic chromosome segregation defects. Mitotic cells of wild-type $(n=1497)$, Suv4-20h double-knockout $(n=1242)$, and rescue MEFs $(\mathrm{DKO}+\mathrm{FL}, n=768$; DKO+M12, $n=687$ ) were assessed for anaphase bridges and lagging chromosomes (the right panel shows representative pictures of these defects). P-values of Student's $t$-test are indicated. Error bars correspond to standard deviation. $(B)$ Mitotic marker analysis. Chromosome spreads of wild-type and Suv4-20h double-knockout cells were stained for specific markers that are known to be important for chromosome segregation. Representative pictures of mitotic chromosomes are shown. $(C)$ Mean distance of CenpA foci in wild-type $(n=458)$, Suv4-20h double-knockout $(n=348)$, DKO+FL $(n=242)$, and DKO+M12 $(n=318)$ mitotic chromosomes. $P$-values of Student's $t$-test are indicated. 
Re-expression of Suv4-20h2 (DKO+FL) or of the Suv420h2 clamp domain (DKO+M12) lead to centromere distances comparable with wild-type cells (Fig. 4C). These data indicate that Suv4-20h2 is important for mediating normal sister chromatid cohesion. Reduced cohesion in Suv4-20h double-knockout cells in turn leads to mitotic abnormalities such as lagging chromosomes and anaphase bridges.

\section{Suv4-20h2 interacts with cohesin}

We thus hypothesized that in addition to having a structural role in heterochromatin, Suv4-20h2 may recruit additional proteins that facilitate sister chromatid cohesion. We performed GST pull-down assays to identify potential interaction partners of Suv4-20h2 using two different C-terminal truncation proteins (Supplemental Fig. S12A). The first region, M5, comprises the clamp domain, whereas the second fragment, M7, contains the very $\mathrm{C}$ terminus that does not localize to heterochromatin (see Fig. 1B). We could clearly precipitate all HP1 isoforms with fragment M5 (Fig. 5A), confirming the direct interaction of HP1 with the Suv4-20h2 clamp domain. Interestingly, additional proteins consistently found to coprecipitate with Suv4-20h2-M5 were subunits of the cohesin complex (Fig. 5A; Supplemental Table S1). The GST pull-down experiments were performed using sonicated nuclear extracts that contain genomic DNA and large chromatin fragments. In order to test whether cohesin indirectly associates with Suv4-20h2 through
DNA, we repeated the GST pull-down assays using extracts that were treated with benzonase to degrade all forms of RNA and DNA. Accordingly, extracts treated with benzonase were devoid of any contaminating DNA (Supplemental Fig. S12B). When using benzonase-treated extracts in GST pull-down assays, we clearly detected binding of both HP1 and cohesin subunits to Suv4-20h2M5 (Fig. 5B). Similar results were obtained when extracts were treated with ethidium bromide, which disrupts DNA-protein interactions (Fig. 5B).

In order to verify that Suv4-20h2 interacts with cohesin subunits in vivo, we performed coimmunoprecipitation experiments using a Suv4-20h2 ${ }^{\text {HA-Flag }}$ knock-in cell line. In this cell line, the endogenous Suv4-20h2 locus is modified to produce a HA-3xFlag-tagged fusion protein, ensuring endogenous expression levels (Supplemental Fig. S12C). We developed a two-step extraction protocol to remove the bulk of cohesin through digestion of the DNA with benzonase (fraction I), followed by salt extraction of Suv4-20h2 and the remaining cohesin (fraction II). Flag affinity purification of Suv4-20h2 from fraction II extracts coprecipitated cohesin subunits (Fig. 5C). In the reverse experiment, cohesin subunit Smcl could coprecipitate Suv4-20h2 ${ }^{\text {HA-Flag }}$ (Fig. 5C). We did not detect interaction of unrelated proteins such as Suz12, confirming the specificity of the Suv4-20h2-cohesin interaction. In the pull-down experiments, we found that Suv4-20h2 fragment M5, containing the clamp domain, interacts with cohesin subunits. To test whether the clamp domain is important to mediate interaction with cohesin, we
A

\begin{tabular}{lccc} 
& \multicolumn{3}{c}{ Suv4-20h2 GST } \\
\cline { 2 - 4 } protein & GST & $\begin{array}{c}\text { M5 } \\
\text { (aa 349-441) }\end{array}$ & $\begin{array}{c}\text { M7 } \\
\text { (aa 409-468) }\end{array}$ \\
Suv4-20h2 & 4 & 112 & 62 \\
HP1 $\alpha$ & 0 & 41 & 0 \\
HP1 $\beta$ & 0 & 40 & 0 \\
HP1 $\gamma$ & 1 & 40 & 0 \\
Smc1 & 0 & 7 & 1 \\
Smc3 & 0 & 3 & 0
\end{tabular}

B

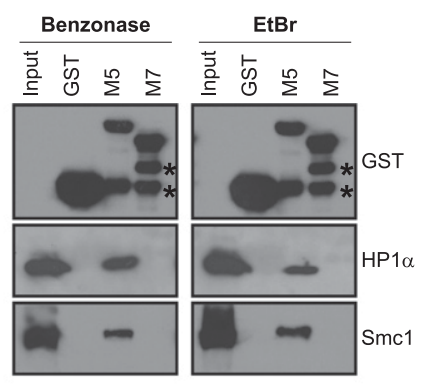

C

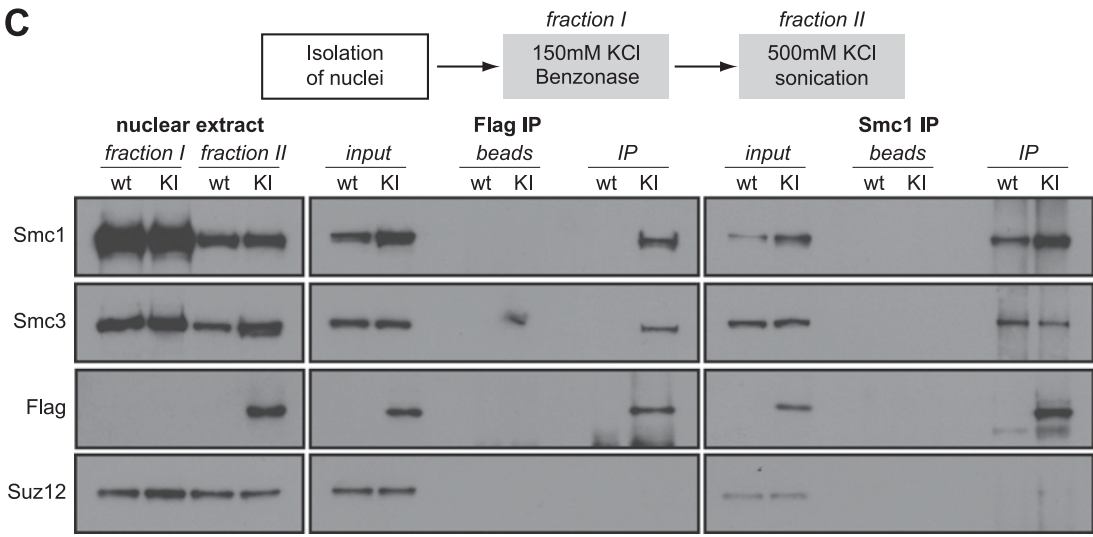

Figure 5. Suv4-20h2 interacts with cohesin subunits. (A) GST pull-down of Suv4-20h2 truncation proteins. Suv4-20h2 truncationsheterochromatin-associated (M5) and disperse nuclear (M7)-were expressed as recombinant GST-tagged proteins, incubated with nuclear extracts, and bound to affinity beads. Mass spectrometry identification of bound proteins revealed HP1 isoforms and two cohesin subunits to specifically interact with Suv4-20h2 fragment M5 (summary of triplicate experiments). The number of unique spectra that were identified for each protein in the mass spectrometry analysis is indicated (Scaffold analysis). The full list of identified proteins is shown in Supplemental Table S1. (B) GST pull-down experiments. Benzonasetreated nuclear extracts contain no detectable DNA contamination. Ethidium bromide treatment disrupts protein-DNA interactions. Western blots for GST pull-down experiments using recombinant GST, Suv420h2-M5, and Suv4-20h2-M7 were probed for GST, HP1 $\alpha$, and Smc1. The Input lane contains the nuclear extract. Degradation products of the GST-tagged proteins are indicated by asterisks. (C) Suv4-20h2 and cohesin interact in vivo. Fractionated nuclear extracts were prepared from wild-type (wt) and Suv4-20h2 ${ }^{\text {HA-Flag }}$ knock-in (KI) ES cells. Suv4-20h2 and Smc1 were precipitated from fraction II extracts using Flag and Smc1 antibodies, respectively. Bound proteins were visualized by Western blotting using Flag, Smc1, Smc3, and Suz12 antibodies. 
performed immunoprecipitation experiments in cells expressing full-length Suv4-20h2 or Suv4-20h2-sM12, which lacks the clamp domain. We detected interaction of cohesin with full-length Suv4-20h2 but not with Suv420h2- $\Delta$ M12 (Supplemental Fig. S12D), suggesting that the clamp domain is important to facilitate interaction with cohesin.

\section{Reduced heterochromatin-associated cohesin in Suv4-20h-deficient cells}

To test whether Suv4-20h2 plays a role in recruiting cohesin to heterochromatin, we performed chromatin

A

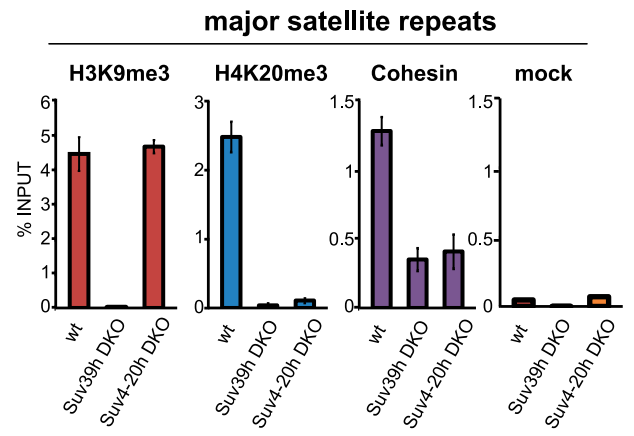

B

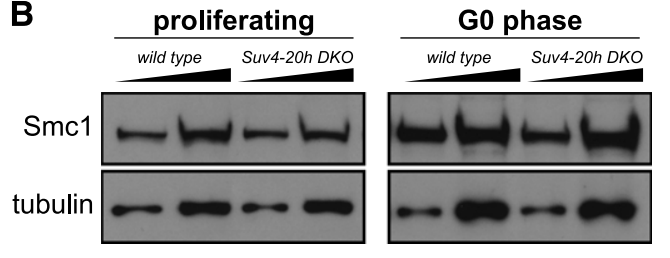

C

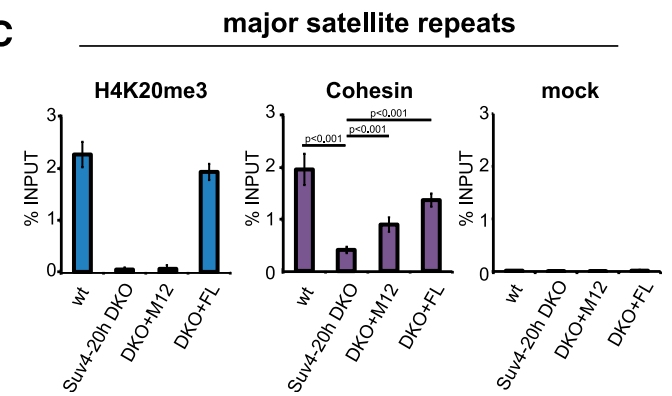

immunoprecipitation (ChIP) experiments for cohesin subunits and tested their enrichment at major satellite repeats and control regions outside of pericentric heterochromatin. In wild-type cells, heterochromatin is enriched for repressive histone modifications (H3K9me3 and H4K20me3) and cohesin subunits (Fig. 6A; Supplemental Fig. S13). Strikingly, in Suv4-20h double-knockout cells, cohesin subunits were strongly reduced at major satellite repeats (Fig. 6A; Supplemental Fig. S13) but not at the control regions where cohesin is recruited through different mechanisms (Parelho et al. 2008; Rubio et al. 2008; Wendt et al. 2008). We observed reduced heterochromatin-associated cohesin in two independent Suv4-20h2

D

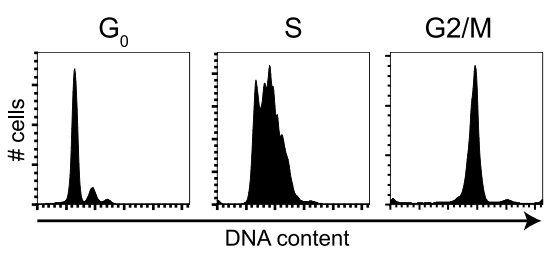

E
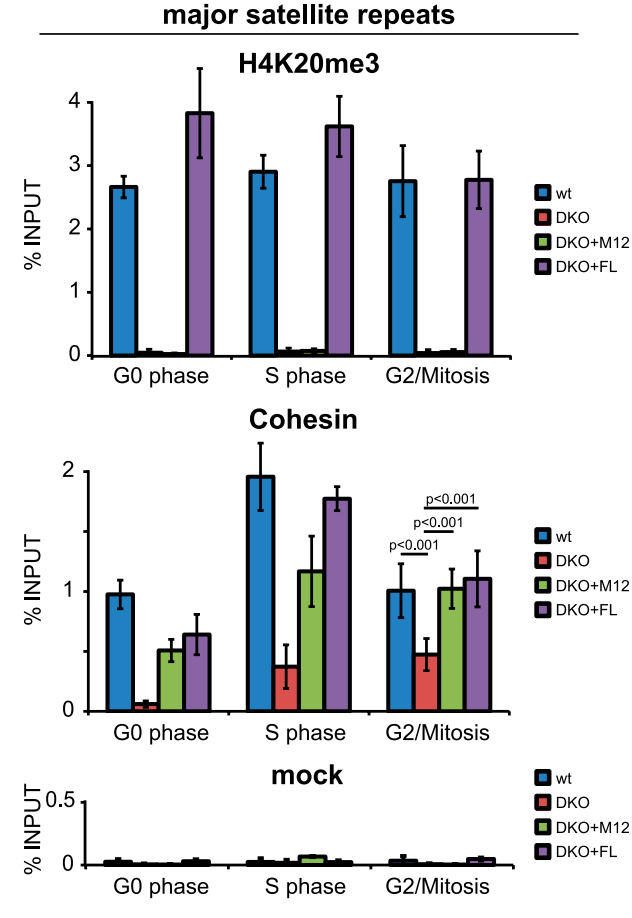

Figure 6. Suv4-20h2 is important for cohesin recruitment to pericentric heterochromatin. (A) Suv39h double-knockout and Suv4-20h double-knockout cells display reduced cohesin levels at pericentric heterochromatin. ChIP analysis of histone modifications and the cohesin subunits Smc3 in wild-type, Suv39h double-knockout, and Suv4-20h double-knockout cells at major satellite repeats. Merge of two experiments in two independent cell lines with three technical replicates each. Error bars represent standard deviation over all experiments. (B) Cohesin levels are not generally impaired in Suv4-20h double-knockout cells. Protein extracts of proliferating (left panel) or G0-arrested (right panel) wild-type and Suv4-20h double-knockout cells were tested for cohesin levels by Western blot for Smc1 (cohesin) and tubulin (loading control). Two different amounts of cell extracts were loaded. (C) Cohesin establishment can be mediated by the Suv4-20h2 clamp domain. ChIP analysis of H4K20me3 and cohesin (Smc3) at major satellite repeats. Expression of fulllength Suv4-20h2 (DKO+FL) restores H4K20me3 and cohesin in Suv4-20h double-knockout cells. Cohesin is partially rescued by expression of the Suv4-20h2 clamp domain (DKO+M12). Merge of two independent experiments with three technical replicates. Error bars represent standard deviation over all experiments. (D) FACS analysis of wild-type cells in G0, S, and M phase. Cells were isolated as described and stained with propidium iodide prior to FACS analysis. (E) Suv4-20h enzymes are essential for cohesin recruitment to heterochromatin. Wild-type, Suv4-20h double-knockout, and rescue cell lines (DKO+M12 and DKO+FL) were harvested in G0, S, and $\mathrm{M}$ phase. ChIP analysis for H3K9me3, H4K20me3, and cohesin (Smc3) at major satellite repeats was performed in two independent experiments with three technical replicates. Error bars represent standard deviation over all experiments. 
knockout and two independent Suv4-20h double-knockout cell lines (Supplemental Fig. S13). Cohesin levels are not generally reduced in Suv4-20h double-knockout cells (Fig. 6B), suggesting specific defects in recruitment of cohesin to heterochromatin. Association of Suv4-20h2 with pericentric heterochromatin depends on Suv39hmediated H3K9me3 and HP1 association. Therefore, we tested cohesin levels in Suv39h double-knockout cells that have lost both $\mathrm{H} 3 \mathrm{~K} 9 \mathrm{me} 3$ and $\mathrm{H} 4 \mathrm{~K} 20 \mathrm{me} 3$ at pericentric heterochromatin (Fig. 6A). Importantly, reduced cohesin levels could also be detected in two independent Suv39h double-knockout cell lines (Fig. 6A; Supplemental Fig. S14), demonstrating that the Suv39hSuv4-20h pathway is important for cohesin recruitment to heterochromatin.

We then asked whether Suv4-20h2 is responsible for cohesin recruitment to heterochromatin by rescue experiments in Suv4-20h double-knockout cells. Expression of full-length Suv4-20h2 (DKO+FL) could rescue both cohesin and H4K20me3 at major satellite repeats (Fig. 6C). Interestingly, the Suv4-20h2 clamp domain (DKO+M12) could also increase cohesin levels at heterochromatin, although this truncation protein lacks the SET domain and thus was unable to restore H4K20me3 (Fig. 6C). Cohesin at control regions was not affected in the different rescue experiments (Supplemental Fig. S15). We conclude that Suv4-20h2 plays an important role in recruiting cohesin to heterochromatic regions through interactions with cohesin subunits.

Suv4-20h2 is important for the initial recruitment of cohesin to pericentric heterochromatin

Finally, we investigated whether Suv4-20h2 is involved in the initial recruitment/maintenance of cohesin at heterochromatin. Loading of cohesin onto chromatin occurs in early G1 phase (Watrin et al. 2006). In the subsequent cell cycle stages, cohesin is maintained on the chromosomes until mitosis. During metaphase, cohesin is removed from chromosome arms by proteolytic cleavage (Hauf et al. 2001). Only cohesin at pericentric heterochromatin is maintained until the onset of anaphase to ensure sister chromatid cohesion (Salic et al. 2004; Tang et al. 2004). In order to investigate whether Suv4$20 \mathrm{~h} 2$ is implicated in cohesin loading or maintenance, we analyzed cohesin levels in different cell cycle stages. We synchronized cells in G0, S, and G2/M phase (Fig. 6D; Supplemental Fig. S16) and prepared chromatin for ChIP analysis. We found that cohesin levels varied only slightly over the cell cycle in wild-type cells (Fig. 6E). In contrast, in Suv4-20h double-knockout cells, cohesin was basically absent from heterochromatic regions in G0 phase, suggesting that Suv4-20h enzymes are crucial for loading and/or maintaining cohesin at heterochromatin. At later stages in the cell cycle (S and G2/M phase), cohesin levels increased (Fig. 6E), indicating that additional, Suv4-20hindependent recruitment mechanisms exist during $S$ phase. The loss of heterochromatin-associated cohesin in Suv4$20 \mathrm{~h}$ double-knockout cells could be rescued by expressing the clamp domain (M12) or full-length Suv4-20h2 (Fig. 6E), whereas cohesin recruitment at unrelated control regions was not affected in the rescue cells (Supplemental Fig. S17). Thus, our data demonstrate that Suv4-20h2 is an important factor for cohesin loading onto heterochromatin.

\section{Discussion}

Heterochromatin is a very abundant chromatin state in mammalian cells, as $>30 \%$ of the mammalian genome is composed of repetitive sequences that need to be silenced. Heterochromatin is therefore characterized by low transcriptional activity and features a less accessible chromatin structure. These special properties of heterochromatin are established in a step-wise manner. First, specific proteins need to recognize heterochromatic sequences (Bulut-Karslioglu et al. 2012). Second, heterochromatin becomes marked with distinct histone modifications that recruit additional binding proteins to ultimately mediate the special properties of this chromatin state. In vivo, heterochromatin is not a stiff entity, but rather a dynamic equilibrium of a protein interaction network. Thus, it can both reduce chromatin accessibility under steady-state conditions and open up chromatin structure in response to specific stimuli; for example, DNA damage (Goodarzi et al. 2008). Here we demonstrate that Suv4-20h2 is an important constituent of this interaction network for regulating chromatin accessibility and long-range chromatin interactions. In ES cells and fibroblasts, these functions do not seem to be shared with Suv4-20h1, which features a different heterochromatin targeting domain that is not homologous to the Suv4$20 \mathrm{~h} 2$ clamp domain and does not bind so tightly to heterochromatin (Supplemental Fig. S18A).

How is Suv4-20h2 integrated into this network and how can it affect heterochromatin structure? Heterochromatin displays abundant $\mathrm{H} 3 \mathrm{~K} 9 \mathrm{me} 3$, which provides a binding interface for HP1 proteins. Although HP1 shows only a weak affinity to $\mathrm{H} 3 \mathrm{~K} 9 \mathrm{me} 3$ in vitro, the high density of H3K9me3 can lead to a high HP1 abundance in heterochromatin. We found that Suv4-20h2 features multiple HP1 interaction sites in its clamp domain, which can explain its stable association with regions that feature high HP1 concentrations. The interaction with multiple $\mathrm{HP} 1$ proteins raises an interesting hypothesis that Suv420h2 might bridge H3K9me3- and HP1-rich chromatin fibers to render chromatin less accessible. In agreement with this view, we found that chromatin in cells lacking Suv4-20h2 is indeed more accessible to nucleases. Notably, the level of Suv4-20h2 can alter the balance within the heterochromatin interaction network and may therefore modulate the functions of its interacting proteins, like HP1. Another protein that may be affected by Suv4-20h2 is the linker histone H1. This is inferred by the observed alterations in the nucleosome repeat length in Suv4-20h double-knockout cells (Fig. 2B), which is a typical feature of cells with reduced levels of histone H1 (Fan et al. 2005). The current knowledge of the topology of the heterochromatin interaction network is insufficient to distinguish direct effects from indirect effects. However, our data demonstrate that Suv4-20h2 
is a central node within this network, and therefore changes of Suv4-20h2 levels lead to drastic alterations in nuclear architecture.

Interestingly, the clamp domain of Suv4-20h2 is necessary and sufficient for chromatin compaction, as Suv4$20 \mathrm{~h}$ double-knockout cells expressing this domain display normal chromatin accessibility. However, the clamp domain is not sufficient to mediate long-range chromatin interactions and condensation of large chromatin domains. Therefore, other domains in Suv4-20h2, such as an active SET domain, or recruitment of additional proteins are required for these functions. An intriguing possibility is that heterochromatin-associated cohesin, which is recruited by Suv4-20h2, is implicated in these long-range interactions (Hadjur et al. 2009; Kagey et al. 2010; Degner et al. 2011). Recent evidence suggests that cohesin may be involved in regulating the condensation of heterochromatic domains. Cohesin is present in a balance between a chromatin-associated form and a free form that is adjusted by a loading-releasing cycle (Kueng et al. 2006; Gause et al. 2010). Perturbation of this balance by knockdown of the cohesin-releasing factor WAPL leads to increased cohesin association with chromatin and a dramatic chromatin compaction phenotype (Seitan and Merkenschlager 2012). However, we could not detect significant perturbations in chromocenter organization in cells lacking the cohesin subunit Scc1/Rad21 (Supplemental Fig. S19). Therefore, we expect that other proteins that interact with Suv4-20h2 outside of the clamp domain are necessary to mediate chromocenter clustering.

Although cohesin appears to be dispensable for nuclear architecture in interphase cells, heterochromatinassociated cohesin is absolutely crucial for sister chromatid cohesion during mitosis. How cohesin is loaded onto chromatin and how the cohesin ring stabilizes interactions between chromatids are currently unclear (Nasmyth 2011). We found that the Suv39h-Suv4-20h pathway is important for the loading of cohesin to pericentric heterochromatin (Fig. 7). Our data are consistent with a study demonstrating that Suv39h-deficient cells display defects in sister chromatid cohesion and chromosome segregation (Koch et al. 2008). Although Koch et al. (2008) could not demonstrate that cohesin levels in Suv39h double-knockout cells were reduced, this may be due to their semiquantitative ChIP analysis, which is not suitable for highly repetitive sequences. We clearly detected reduced cohesin levels at major satellite repeats in different Suv39h double-knockout, Suv4-20h double-knockout, and Suv4-20h2 knockout cell lines. In none of these cell lines, cohesin was completely lost from heterochromatin, suggesting additional loading pathways. Based on our data, we conclude that the primary function of Suv39h enzymes is to prepare pericentric heterochromatin for HP1 recruitment, which is a prerequisite for stable association of Suv4-20h2. Cohesion recruitment is then facilitated through interactions of cohesin subunits with Suv4-20h2 and possibly additional factors. Suv4-20h1 does not interact with cohesin and is therefore unlikely to contribute to cohesin recruitment (Supplemental Fig. $\mathrm{S} 18 \mathrm{C})$. Interestingly, cohesin recruitment can be mediated at least partially through the Suv4-20h2 clamp domain. As this domain can interact with cohesin and also induce chromatin compaction, it is not possible to distinguish which of the two functions is more relevant for cohesin recruitment to heterochromatin.

The cell cycle analysis revealed that Suv4-20h2 is essential for cohesin loading in G0 phase. During later stages of the cell cycle, Suv4-20h2-independent pathways can recruit cohesin to heterochromatin. This would explain why mitosis is not completely blocked and why comparably mild mitotic phenotypes were detected in Suv4-20h-deficient cells. Importantly, our data are consistent with other reports that demonstrate that the fidelity of mitosis is already compromised when heterochromatinassociated cohesin levels are only reduced (Eckert et al. 2007). A low level of mitotic defects can therefore ensure survival of the cells but contributes to genomic instability.

Dysregulation of pericentric heterochromatin has been suggested to play important roles in cancer development and progression (Hahn et al. 2010; Zhu et al. 2011). Cancer cells are frequently characterized by genomic instability and cohesion defects (Thompson et al. 2010), but the mechanisms are still poorly understood. Previous analyses have shown that a reduced level of H4K20me3, which is an indirect measure for the presence of Suv4-20h enzymes, characterizes different human tumors (Fraga et al. 2005). In light of our data, we hypothesize that Suv4$20 \mathrm{~h} 2$ might be an important cohesin recruitment factor in human cells. Its dysregulation could lead to reduced levels of heterochromatin-associated cohesin, which in turn contributes to the genomic instability that is characteristic of many human tumors and could explain the negative survival prognosis with tumors that have low H4K20me3 levels (Van Den Broeck et al. 2008; Schneider et al. 2011).

\section{Materials and methods}

\section{FRAP}

FRAP measurements were performed in MEF and ES cell lines after transient expression of EGFP-tagged proteins. Analysis of the recovery curves of the intensity integrated over the region of interest (ROI) was done using FREDIS software (Muller et al. 2009). For Figure 1, the averaged recovery curves were fitted to a diffusion model or a reaction diffusion model that incorporates both diffusion and binding processes.

\section{HP1 interaction test}

GST fusion proteins of Suv4-20h2, HP1 $\alpha, \mathrm{HP} 1 \beta$, and HP1 $\gamma$ were expressed in Escherichia coli and purified using glutathioneS-sepharose beads (Amersham Biosciences). The GST tag was subsequently removed using PreScission protease. Interaction tests were performed by incubating $5 \mu \mathrm{g}$ of GST-Suv4-20h2 fusion protein with $5 \mu \mathrm{g}$ of either HP1 $1 \alpha, \mathrm{HP} 1 \beta$, or HP $1 \gamma$ for $1 \mathrm{~h}$ at room temperature on a rotating wheel.

\section{Chromatin accessibility assay}

Nuclei of wild-type, Suv4-20h2 knockout, and Suv4-20h2 double-knockout ES cells and wild-type, Suv4-20h double-knockout, 
Hahn et al.

A

\section{Suv4-20h2}
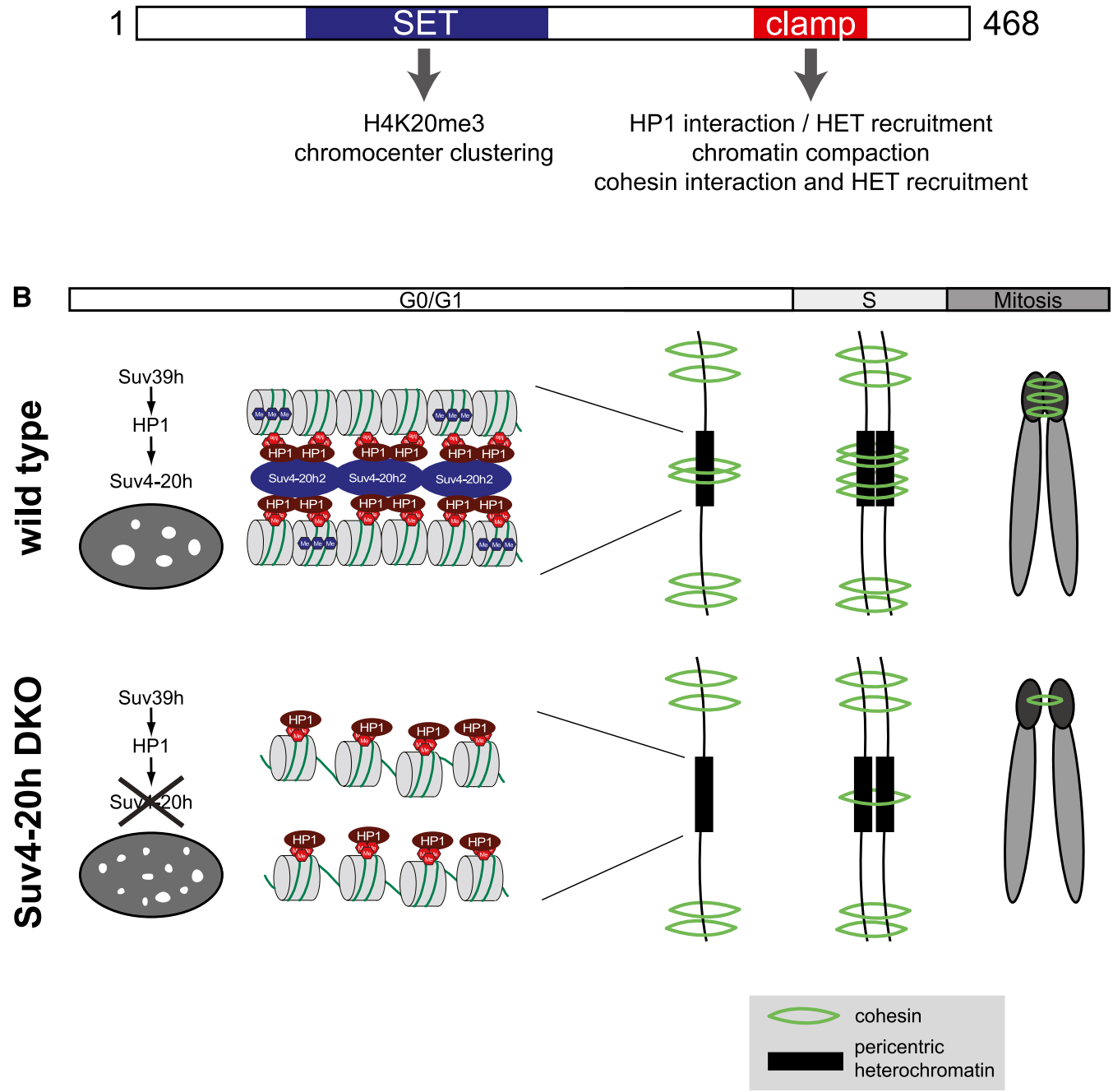

Figure 7. Model for Suv4-20h2-mediated chromatin compaction. (A) Functional domains in Suv4-20h2. The SET domain is the catalytic domain that induces H4K20me3. Establishing this modification is important to mediate chromocenter clustering. The clamp domain is essential to recruit Suv4-20h2 to pericentric heterochromatin. The clamp domain also mediates the Suv4-20h2-cohesin interaction and thus the recruitment of cohesin to heterochromatin. (B) Model showing the role of the Suv39h-HP1-Suv4-20h pathway for chromatin compaction and cohesin recruitment to pericentric heterochromatin. Based on our data, we propose that Suv4-20h2 can mediate interactions between chromatin fibers by binding to H3K9me3-rich and HP1-rich domains. The loss of Suv4-20h enzymes leads to a compromised heterochromatin organization (reduced chromatin compaction and chromocenter scattering) although H3K9me3 and HP1 are still present at heterochromatic regions. In G0/G1 cells, the interaction with Suv4-20h2 is important for cohesin recruitment to pericentric heterochromatin. Cohesin is not completely lost from mitotic chromosomes due to alternative, Suv4-20h-independent loading pathways during S/G2 phase.

$\mathrm{DKO}+\mathrm{FL}$, and DKO+M12 fibroblast cell lines were digested with different amounts of MNase (Sigma) according to Gilbert et al. (2007). Genomic DNA was purified and separated on a $1 \%$ agarose gel or loaded onto a DNA LabChip (Agilent Technologies).

\section{D-SIM}

Superresolution 3D-SIM of immunofluorescently labeled and DAPI-stained nuclei was performed as previously described (Schermelleh et al. 2008) on a DeltaVision OMX V3 system (Applied Precision) equipped with a $100 \times / 1.40$ NA PlanApo oil immersion objective (Olympus) and Cascade II:512 EMCCD cameras (Photometrics) using 405-nm and 592-nm diode laser.

\section{Mitotic abnormalities}

To quantify the number of abnormal mitotic figures in MEF cells, mitotic cells were collected by shake-off, spun onto a glassbottomed 96-black well plate (Greiner Bio-One) for $5 \mathrm{~min}$ at $400 g$, fixed in $4 \%$ formaldehyde, and stained with VectaShield containing DAPI.

\section{Coimmunoprecipitation}

Nuclei of wild-type and Suv4-20h2 ${ }^{\text {HA-Flag }}$ ES cells were sequentially extracted with low-salt (fraction I) and high-salt (fraction II) immunoprecipitation buffer and incubated with $5 \mu \mathrm{g}$ of either 
Flag M2 antibody (Sigma) or Smc1 antibody (Bethyl Laboratories) coupled to ProteinA/G magnetic beads (Dynabeads, Invitrogen) overnight at $4{ }^{\circ} \mathrm{C}$ on a rotating wheel. Bound proteins were separated on SDS-polyacrylamide gels and analyzed by Western blotting.

\section{ChIP}

ChIP experiments were performed as in Samoshkin et al. (2012) using the following antibodies: anti-H3K9me3 (Abcam, \#ab8898), anti-H4K20me3 (Active Motif, \#39180.3918; or Millipore, \#07-463), anti-Rad21 (Abcam, \#ab992), and anti-Smc3 (Abcam, \#ab92631.

\section{Automatic 3D quantification of FISH foci}

Major satellite FISH experiments were performed according to Markaki et al. (2013). To determine quantitative information of FISH major satellite repeats from the acquired two-channel 3D confocal microscopy images, we developed a fully automatic 3D image analysis approach consisting of 3D cell nuclei segmentation and $3 \mathrm{D}$ foci segmentation.

\section{Acknowledgments}

We thank Alexander Nuber for technical help. We are grateful to Thomas Cremer for sending major satellite FISH probes and protocols. We thank Jan-Michael Peters for sending antibodies, and Matthias Merkenschlager for sharing the Sccl conditional knockout cell lines. We are indebted to Jerome Dejardin for discussions and sharing unpublished data. The work of G.S., K. Rippe, H.L., and K. Rohr was funded by the BMBF project EpiSys in the SysTec program. Additional support was from the Deutsche Forschungsgemeinschaft (SFB-TR5 and SFB684) to L.S., H.L., and G.S. H.v.M. was supported by the Fritz Thyssen Stiftung (AZ. 10.05.1.165).

\section{References}

Bulut-Karslioglu A, Perrera V, Scaranaro M, de la Rosa-Velazquez IA, van de Nobelen S, Shukeir N, Popow J, Gerle B, Opravil S, Pagani M, et al. 2012. A transcription factor-based mechanism for mouse heterochromatin formation. Nat Struct Mol Biol 19: 1023-1030.

Cheutin T, McNairn AJ, Jenuwein T, Gilbert DM, Singh PB, Misteli T. 2003. Maintenance of stable heterochromatin domains by dynamic HP1 binding. Science 299: 721-725.

Degner SC, Verma-Gaur J, Wong TP, Bossen C, Iverson GM, Torkamani A, Vettermann C, Lin YC, Ju Z, Schulz D, et al. 2011. CCCTC-binding factor (CTCF) and cohesin influence the genomic architecture of the Igh locus and antisense transcription in pro-B cells. Proc Natl Acad Sci 108: 95669571.

Eckert CA, Gravdahl DJ, Megee PC. 2007. The enhancement of pericentromeric cohesin association by conserved kinetochore components promotes high-fidelity chromosome segregation and is sensitive to microtubule-based tension. Genes Dev 21: 278-291.

Fan Y, Nikitina T, Zhao J, Fleury TJ, Bhattacharyya R, Bouhassira EE, Stein A, Woodcock CL, Skoultchi AI. 2005. Histone H1 depletion in mammals alters global chromatin structure but causes specific changes in gene regulation. Cell 123: 11991212.

Fraga MF, Ballestar E, Villar-Garea A, Boix-Chornet M, Espada J, Schotta G, Bonaldi T, Haydon C, Ropero S, Petrie K, et al. 2005. Loss of acetylation at Lys16 and trimethylation at
Lys20 of histone $\mathrm{H} 4$ is a common hallmark of human cancer. Nat Genet 37: 391-400.

Gause M, Misulovin Z, Bilyeu A, Dorsett D. 2010. Dosagesensitive regulation of cohesin chromosome binding and dynamics by Nipped-B, Pds5, and Wapl. Mol Cell Biol 30: 4940-4951.

Gilbert N, Thomson I, Boyle S, Allan J, Ramsahoye B, Bickmore WA. 2007. DNA methylation affects nuclear organization, histone modifications, and linker histone binding but not chromatin compaction. J Cell Biol 177: 401-411.

Goodarzi AA, Noon AT, Deckbar D, Ziv Y, Shiloh Y, Lobrich M, Jeggo PA. 2008. ATM signaling facilitates repair of DNA double-strand breaks associated with heterochromatin. Mol Cell 31: 167-177.

Guenatri M, Bailly D, Maison C, Almouzni G. 2004. Mouse centric and pericentric satellite repeats form distinct functional heterochromatin. J Cell Biol 166: 493-505.

Hadjur S, Williams LM, Ryan NK, Cobb BS, Sexton T, Fraser P, Fisher AG, Merkenschlager M. 2009. Cohesins form chromosomal cis-interactions at the developmentally regulated IFNG locus. Nature 460: 410-413.

Hahn M, Dambacher S, Schotta G. 2010. Heterochromatin dysregulation in human diseases. I Appl Physiol 109: 232242.

Hauf S, Waizenegger IC, Peters JM. 2001. Cohesin cleavage by separase required for anaphase and cytokinesis in human cells. Science 293: 1320-1323.

Kagey MH, Newman JJ, Bilodeau S, Zhan Y, Orlando DA, van Berkum NL, Ebmeier CC, Goossens J, Rahl PB, Levine SS, et al. 2010. Mediator and cohesin connect gene expression and chromatin architecture. Nature 467: 430-435.

Koch B, Kueng S, Ruckenbauer C, Wendt KS, Peters JM. 2008. The Suv39h-HP1 histone methylation pathway is dispensable for enrichment and protection of cohesin at centromeres in mammalian cells. Chromosoma 117: 199-210.

Kueng S, Hegemann B, Peters BH, Lipp JJ, Schleiffer A, Mechtler K, Peters JM. 2006. Wapl controls the dynamic association of cohesin with chromatin. Cell 127: 955-967.

Lengronne A, Katou Y, Mori S, Yokobayashi S, Kelly GP, Itoh T, Watanabe Y, Shirahige K, Uhlmann F. 2004. Cohesin relocation from sites of chromosomal loading to places of convergent transcription. Nature 430: 573-578.

Markaki Y, Smeets D, Cremer M, Schermelleh L. 2013. Fluorescence in situ hybridization applications for super-resolution 3D structured illumination microscopy. Methods Mol Biol 950: 43-64.

Meshorer E, Yellajoshula D, George E, Scambler PJ, Brown DT, Misteli T. 2006. Hyperdynamic plasticity of chromatin proteins in pluripotent embryonic stem cells. Dev Cell 10: 105116.

Muller KP, Erdel F, Caudron-Herger M, Marth C, Fodor BD, Richter M, Scaranaro M, Beaudouin J, Wachsmuth M, Rippe K. 2009. Multiscale analysis of dynamics and interactions of heterochromatin protein 1 by fluorescence fluctuation microscopy. Biophys J 97: 2876-2885.

Nasmyth K. 2011. Cohesin: A catenase with separate entry and exit gates? Nat Cell Biol 13: 1170-1177.

Nicetto D, Hahn M, Jung J, Schneider TD, Straub T, David R, Schotta G, Rupp RA. 2013. Suv4-20h histone methyltransferases promote neuroectodermal differentiation by silencing the pluripotency-associated oct-25 gene. PLoS Genet 9: e1003188.

Nonaka N, Kitajima T, Yokobayashi S, Xiao G, Yamamoto M, Grewal SI, Watanabe Y. 2002. Recruitment of cohesin to heterochromatic regions by Swi6/HP1 in fission yeast. Nat Cell Biol 4: 89-93. 
Parelho V, Hadjur S, Spivakov M, Leleu M, Sauer S, Gregson HC, Jarmuz A, Canzonetta C, Webster Z, Nesterova T, et al. 2008. Cohesins functionally associate with CTCF on mammalian chromosome arms. Cell 132: 422-433.

Peters AH, O'Carroll D, Scherthan H, Mechtler K, Sauer S, Schofer C, Weipoltshammer K, Pagani M, Lachner $M$, Kohlmaier A, et al. 2001. Loss of the Suv39h histone methyltransferases impairs mammalian heterochromatin and genome stability. Cell 107: 323-337.

Rubio ED, Reiss DJ, Welcsh PL, Disteche CM, Filippova GN, Baliga NS, Aebersold R, Ranish JA, Krumm A. 2008. CTCF physically links cohesin to chromatin. Proc Natl Acad Sci 105: 8309-8314.

Salic A, Waters JC, Mitchison TJ. 2004. Vertebrate shugoshin links sister centromere cohesion and kinetochore microtubule stability in mitosis. Cell 118: 567-578.

Samoshkin A, Dulev S, Loukinov D, Rosenfeld JA, Strunnikov AV. 2012. Condensin dysfunction in human cells induces nonrandom chromosomal breaks in anaphase, with distinct patterns for both unique and repeated genomic regions. Chromosoma 121: 191-199.

Schermelleh L, Carlton PM, Haase S, Shao L, Winoto L, Kner P, Burke B, Cardoso MC, Agard DA, Gustafsson MG, et al. 2008. Subdiffraction multicolor imaging of the nuclear periphery with $3 \mathrm{D}$ structured illumination microscopy. Science 320: 1332-1336.

Schneider AC, Heukamp LC, Rogenhofer S, Fechner G, Bastian PJ, von Ruecker A, Muller SC, Ellinger J. 2011. Global histone H4K20 trimethylation predicts cancer-specific survival in patients with muscle-invasive bladder cancer. $B J U$ Int 108: E290-E296.

Schotta G, Lachner M, Sarma K, Ebert A, Sengupta R, Reuter G, Reinberg D, Jenuwein T. 2004. A silencing pathway to induce $\mathrm{H} 3-\mathrm{K} 9$ and $\mathrm{H} 4-\mathrm{K} 20$ trimethylation at constitutive heterochromatin. Genes Dev 18: 1251-1262.

Schotta G, Sengupta R, Kubicek S, Malin S, Kauer M, Callen E, Celeste A, Pagani M, Opravil S, De La Rosa-Velazquez IA, et al. 2008. A chromatin-wide transition to H4K20 monomethylation impairs genome integrity and programmed DNA rearrangements in the mouse. Genes Dev 22: 20482061.

Seitan VC, Merkenschlager M. 2012. Cohesin and chromatin organisation. Curr Opin Genet Dev 22: 93-100.

Souza PP, Volkel P, Trinel D, Vandamme J, Rosnoblet C, Heliot L, Angrand PO. 2009. The histone methyltransferase SUV420H2 and heterochromatin proteins HP1 interact but show different dynamic behaviours. BMC Cell Biol 10: 41.

Tang Z, Sun Y, Harley SE, Zou H, Yu H. 2004. Human Bub1 protects centromeric sister-chromatid cohesion through Shugoshin during mitosis. Proc Natl Acad Sci 101: 1801218017.

Thompson SL, Bakhoum SF, Compton DA. 2010. Mechanisms of chromosomal instability. Curr Biol 20: R285-R295.

Ting DT, Lipson D, Paul S, Brannigan BW, Akhavanfard S, Coffman EJ, Contino G, Deshpande V, Iafrate AJ, Letovsky S, et al. 2011. Aberrant overexpression of satellite repeats in pancreatic and other epithelial cancers. Science 331: 593-596.

Van Den Broeck A, Brambilla E, Moro-Sibilot D, Lantuejoul S, Brambilla C, Eymin B, Khochbin S, Gazzeri S. 2008. Loss of histone H4K20 trimethylation occurs in preneoplasia and influences prognosis of non-small cell lung cancer. Clin Cancer Res 14: 7237-7245.

Vermeulen M, Eberl HC, Matarese F, Marks H, Denissov S, Butter F, Lee KK, Olsen JV, Hyman AA, Stunnenberg HG, et al. 2010. Quantitative interaction proteomics and genome- wide profiling of epigenetic histone marks and their readers. Cell 142: 967-980.

Watrin E, Schleiffer A, Tanaka K, Eisenhaber F, Nasmyth K, Peters JM. 2006. Human Scc4 is required for cohesin binding to chromatin, sister-chromatid cohesion, and mitotic progression. Curr Biol 16: 863-874.

Wendt KS, Yoshida K, Itoh T, Bando M, Koch B, Schirghuber E, Tsutsumi S, Nagae G, Ishihara K, Mishiro T, et al. 2008. Cohesin mediates transcriptional insulation by CCCTCbinding factor. Nature 451: 796-801.

Zhu Q, Pao GM, Huynh AM, Suh H, Tonnu N, Nederlof PM, Gage FH, Verma IM. 2011. BRCA1 tumour suppression occurs via heterochromatin-mediated silencing. Nature 477: 179184. 


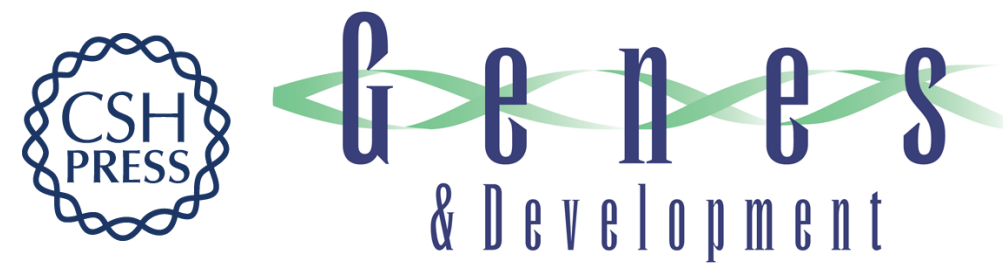

\section{Suv4-20h2 mediates chromatin compaction and is important for cohesin recruitment to heterochromatin}

Matthias Hahn, Silvia Dambacher, Stanimir Dulev, et al.

Genes Dev. 2013, 27: originally published online April 18, 2013

Access the most recent version at doi:10.1101/gad.210377.112

\section{Supplemental http://genesdev.cshlp.org/content/suppl/2013/04/11/gad.210377.112.DC1 Material}

References This article cites 42 articles, 14 of which can be accessed free at: http://genesdev.cshlp.org/content/27/8/859.full.html\#ref-list-1

\section{License}

Email Alerting

Receive free email alerts when new articles cite this article - sign up in the box at the top Service

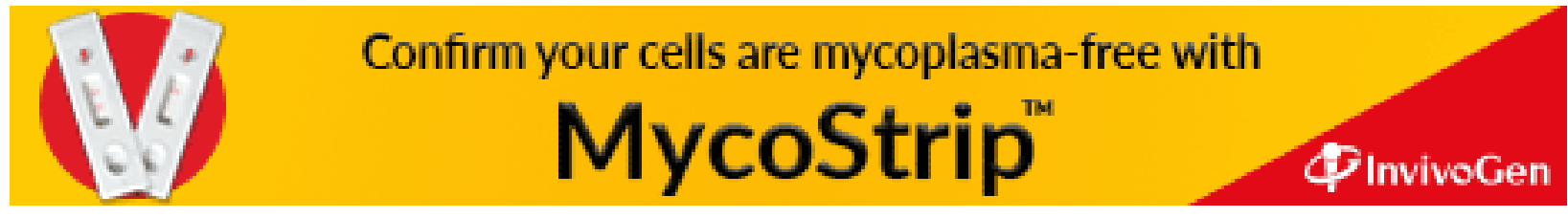

